\title{
A Retrospective Study of Clinical Profile of Stroke Victims in Coimbatore Medical College Hospital
}

\author{
Dr.Praveen Kumar.P ${ }^{1}$ Dr.Priyanka Devi.P ${ }^{2}$ Dr.Athmika. $N^{3}$ \\ ${ }^{1}$ Junior ResidentInGeneral Medicine,Coimbatore Medical College Hospital,Coimbatore,Tamilnadu. \\ ${ }^{2}$ Resident, PSGIMSR, Coimbatore., \\ ${ }^{3}$ Resident, Coimbatore Medical College Hospital.
}

\begin{abstract}
Background: Stroke is one of the leading causes of morbidity \& mortality in India. After coronary heart disease \&cancer stroke is the third commonest cause of death worldwide. Indian studies have shown a stroke prevalence of $471 / 100000$ population. The objective was to study the clinical profile, risk factors, neurological characters, pattern of brain stroke, areas of brain affected as per CT scan findings in patients admitted in Coimbatore Medical College and Hospital,

Methods: This is a retrospective study of all patients managed for cerebrovascular accident in the medical ward of Coimbatore medical college and hospital, Tamilnadu from January 1, 2016 to June 30, 2016.

Results: The cerebrovascular accident is more common in males (59.7\%) than females (40.3\%). Most common age group was 61-70 years (32.8\%). Most common clinical feature was hemiplegia (72.6\%). Most common risk factor was Hypertension (34\%) followed by past h/o cerebrovascular stroke (15\%), smoking (14\%), dyslipidemia (13\%). Most common type of stroke was ischemic (74.6\%) \& hemorrhagic was 2nd (22.9\%). In ischemic stroke most common involved areas were parietal (33.7\%), frontal (16.7\%). In hemorrhagic stroke most common site was thalamus (24.7\%) followed by ventricular (17.5\%).
\end{abstract}

Conclusions: The cerebrovascular accident cases were having male predominance with Hypertension was the most common risk factor and most common type of stroke was ischemic.

Keywords: Cerebrovascular stroke, Ischemic stroke, Hemorrhagic stroke

\section{Introduction}

Stroke is a devastating and disabling disease with significant amount of residual deficit leading on to social and economic loss. It is defined as a rapidly developing signs of focal (or global) disturbance of cerebral function with symptoms lasting for $\geq 24$ hours, or leading to death with no apparent cause other than vascular origin. 1 It is a collection of clinical syndromes resulting from cerebral ischemia to intracranial hemorrhage. In the western world, it is the 3rd most common cause of morbidity and mortality.2

Some of the recent studies have demonstrated the stroke pattern to considerable extent in our country with a prevalence rate $471 / 100000$ population. 3 Recent studies identified that $7 \%$ of medical and $45 \%$ of neurological admissions were due to stroke with a mortality rate of $9 \%$ at time of discharge and $20 \%$ at 1 month.4 Hypertension, alcoholism, smoking \& dyslipidemia are the most common causes of stroke among the elderly,5 and smoking, alcoholism, increased body mass index, DM and hypertension are significantly associated with stroke among young people.

Ischemic stroke accounts for 50\%-85\% of all strokes worldwide. 7 Hemorrhagic stroke are due to subarachnoid hemorrhage or intracerebral hemorrhage, they account for $1 \%-7 \%$ and $7 \%-27 \%$ respectively of all cases of stroke worldwide.7

The Indian national commission on macro-economics and health has estimated that the number of stroke cases will increase from 1081480 in 2000 to 1667372 in 2015.8 The global burden of disease Studies projects that the total deaths from stroke in India will surpass established market prevalence by the year 2020 . Hence this study was undertaken in our region to study various aspects of stroke which will help young doctors to deal with this deadly and disabling disease.

\section{Methods}

This is a retrospective study of 200 cases managed for acute stroke in the medical ward of Coimbatore medical college and hospital, Tamilnadu from January 1, 2016 to June 30, 2016. The case sheets of the patients were retrieved from the medical records department of the hospital and relevant data extracted and analyzed.

\section{Inclusion Criteria}

1) All pts above of age 18 yrs\& having clinical \& CT confirmed diagnosis of stoke.

Exclusion Criteria 
1) Pts below 18 .

2) Stroke due to trauma.

3) Patients medical records which were not showing CT confirmed diagnosis.

The data obtained were analyzed using SPSS version 21.0 software. Results were expressed in frequencies and percentages. The level of significance was set as $\mathrm{p}<0.05$.

\section{Incidence Of Age}

\section{Results}

The age range was from 26 years to 100 years with mean age of 59 years. In this study youngest pt was 26 years \& oldest was 92 years old. The incidence of stroke is maximum in the age group of 51-60 years which comprises of $30.5 \%$ of total pts, as shown in Table 1 . Young stroke (age $\leq 40$ years) comprised of $11 \%$ of all pts.

Table - 1 Frequency and percentage of cases according to age group

\begin{tabular}{|c|c|c|}
\hline $21-30$ & 4 & $2 \%$ \\
\hline $31-40$ & 18 & $9 \%$ \\
\hline $41-50$ & 35 & $17.5 \%$ \\
\hline $51-60$ & 61 & $30.5 \%$ \\
\hline $61-70$ & 58 & $29 \%$ \\
\hline $71-80$ & 20 & $10 \%$ \\
\hline $81-90$ & 4 & $2 \%$ \\
\hline TOTAL & 200 & $100 \%$ \\
\hline
\end{tabular}

\section{Sex Distribution Of Stoke Pts}

Out of 200 pts, 114 were males \& 86 were females as shown in Table 2.

The male to female ratio was 1.3:1.

From above observation it can be concluded that incidence of stroke is more common in male sex.

Table - 2 Sex Wise Distribution

\begin{tabular}{|c|c|c|}
\hline SEX & FREQUENCY & PERCENT \\
\hline MALE & $\mathbf{1 1 4}$ & $\mathbf{5 7 \%}$ \\
\hline FEMALE & $\mathbf{8 6}$ & $\mathbf{4 3 \%}$ \\
\hline TOTAL & $\mathbf{2 0 0}$ & $\mathbf{1 0 0 \%}$ \\
\hline
\end{tabular}

\section{Clinical Presentation Of Stroke Pts}

In our study as shown in Table 3, most common clinical presentation was hemiplegia which was $47 \%$ followed by speech involvement (17\%), altered sensorium (14\%), giddiness (12\%), convulsions (5\%), vomiting $\&$ headache $(5 \%)$.

Table $\mathbf{- 3}$ Frequency Of Clinical Features In Stroke Patients

\begin{tabular}{|c|c|c|}
\hline CLINICAL FEATURES & FREQUENCY & PERCENT \\
\hline HEMIPLEGIA & $\mathbf{9 4}$ & $\mathbf{4 7 \%}$ \\
\hline SPEECH INVOLVEMENT & $\mathbf{3 4}$ & $\mathbf{1 7 \%}$ \\
\hline GIDDINESS & $\mathbf{2 4}$ & $\mathbf{1 2 \%}$ \\
\hline CONVULSIONS & $\mathbf{1 0}$ & $\mathbf{5 \%}$ \\
\hline ALTERED SENSORIUM & $\mathbf{2 8}$ & $\mathbf{1 4 \%}$ \\
\hline HEADACHE \& VOMITTING & $\mathbf{1 0}$ & $\mathbf{5 \%}$ \\
\hline TOTAL & $\mathbf{2 0 0}$ & $\mathbf{1 0 0 \%}$ \\
\hline
\end{tabular}

\section{Prevalence Of Risk Factors In Stroke Pts}

In our study most common risk factor was hypertension with $57 \%$ incidence followed by diabetes mellitus $45.5 \%$, dyslipidemia 42\%, past h/o CAD 26.5\%. Smoking seen in 70\%, alcohol 54\%. 4 pts had past H/o of malignancy \& 8 pt was having rheumatic valvular disease, as shown in Table 4.

Table - 4 Frequency Of Risk Factors In Stroke

\begin{tabular}{|l|c|c|}
\hline \multicolumn{1}{|c|}{ RISK FACTORS } & FREQUENCY & PERCENT \\
\hline HYPERTENSION & $\mathbf{1 0 4}$ & $\mathbf{5 7 \%}$ \\
\hline DIABETICS & $\mathbf{9 1}$ & $\mathbf{4 5 . 5 \%}$ \\
\hline PAST H/O CAD & $\mathbf{5 3}$ & $\mathbf{2 6 . 5 \%}$ \\
\hline DYSLIPIDEMIA & $\mathbf{8 4}$ & $\mathbf{4 2 \%}$ \\
\hline ALCOHOL & $\mathbf{1 0 8}$ & $\mathbf{5 4 \%}$ \\
\hline SMOKING & $\mathbf{1 4 0}$ & $\mathbf{7 0 \%}$ \\
\hline
\end{tabular}




\begin{tabular}{|l|c|c|}
\hline PAST H/O CVD & $\mathbf{3 8}$ & $\mathbf{1 9 \%}$ \\
\hline RHD & $\mathbf{8}$ & $\mathbf{4 \%}$ \\
\hline H/O CANCER & $\mathbf{4}$ & $\mathbf{2 \%}$ \\
\hline
\end{tabular}

\section{Type Of Stroke}

In our study as shown in Table 5, 154 pts (77\%) suffered ischemic stroke \& 46 pts (43\%) suffered hemorrhagic stroke. So most common type of stroke was is cerebral infarction. Out of 154 ischemic stroke pt 88 $(57.1 \%)$ were males \& $66(42.9 \%)$ were females. Out of 46 hemorrhagic stroke pts $26(56.5 \%)$ were males \& 20 were females $(43.4 \%)$.

Table - 5 Gender Wise Frequency Of Different Types Of Stroke

\begin{tabular}{|c|c|c|c|}
\hline GENDER & ISCHAEMIC STROKE & $\begin{array}{c}\text { HEMORRHAGIC } \\
\text { STROKE }\end{array}$ & TOTAL \\
\hline MALE & $\mathbf{8 8}$ & $\mathbf{2 6}$ & $\mathbf{1 1 4}$ \\
& $\mathbf{5 7 . 1 \%}$ & $\mathbf{5 6 . 5 2 \%}$ & $\mathbf{5 7 \%}$ \\
\hline FEMALE & $\mathbf{6 6}$ & $\mathbf{2 0}$ & $\mathbf{8 6}$ \\
& $\mathbf{4 2 . 9 \%}$ & $\mathbf{4 3 . 4 8 \%}$ & $\mathbf{4 3 \%}$ \\
\hline TOTAL & $\mathbf{1 5 4}$ & $\mathbf{4 6}$ & $\mathbf{2 0 0}$ \\
\hline
\end{tabular}

\section{Topographic Distribution Of Hemorrhage}

In our study most common site of hemorrhage was capsuloganglionic $(21.7 \%)$ followed by parietal $(17.4 \%)$ as shown in Table 6.

\section{Topographic Distribution Of Infarct}

In our study most common site of infarct was capsuloganglionic( 37\%), followed by parietal (18.2\%) followed by external capsule (10.4\%), as shown in Table 6.

Thus findings were favoring middle cerebral artery territory involvement.

Table - 6 Radiological Distribution Of Infectant And Hemorrhage

\begin{tabular}{|c|c|c|c|c|}
\hline AREAS AFFECTED & \multicolumn{2}{|c|}{$\begin{array}{c}\text { CEREBRAL } \\
\text { HEMORRAHAGE }\end{array}$} & \multicolumn{2}{|c|}{$\begin{array}{l}\text { CEREBRAL } \\
\text { INFARCT }\end{array}$} \\
\hline PONS & 4 & $8.7 \%$ & 7 & $4.5 \%$ \\
\hline MIDBRAIN & 2 & $4.3 \%$ & 4 & $2.6 \%$ \\
\hline THALAMUS & 4 & $8.7 \%$ & 2 & $1.3 \%$ \\
\hline BASAL GANGLIA & 4 & $8.7 \%$ & 4 & $2.6 \%$ \\
\hline VENTRICULAR & & & 4 & $2.6 \%$ \\
\hline INTERNAL CAPSULE & 10 & $21.7 \%$ & 57 & $37 \%$ \\
\hline EXTERNAL CAPSULE & 4 & $8.7 \%$ & 16 & $10.4 \%$ \\
\hline CEREBELLAR & 4 & $8.7 \%$ & 10 & $6.5 \%$ \\
\hline FRONTAL & 2 & $4.3 \%$ & 8 & $5.2 \%$ \\
\hline PARIETAL & 8 & $17.4 \%$ & 28 & $18.2 \%$ \\
\hline OCCIPITAL & 2 & $4.3 \%$ & 10 & $6.5 \%$ \\
\hline $\begin{array}{c}\text { MEDULLA } \\
\text { OBLANGATA }\end{array}$ & 2 & $4.3 \%$ & 4 & $2.6 \%$ \\
\hline TOTAL & \multicolumn{2}{|l|}{46} & \multicolumn{2}{|c|}{154} \\
\hline
\end{tabular}

\section{Discussion}

The mean age observation of 59 in our study which correlates with study done by Maskey et al.9 (mean age 63). The common age group involved was between 51-60 years which closely correlates with study done by Ukoha Ob et al.11 \&Maskey et al.9

Young stroke (age $\leq 40$ years) comprised of $11 \%$ of all pts witch closely correlates with study done by Abdu Sallamet al.16 (13.6\%), Gauri et al.12 (19\%), P. Chitrambalam et al.13 (20\%).

The male to female ratio was $1.3: 1$. Which correlates with study of Aiyaret al.14 (1.9:1). So it can be concluded that incidence of stroke is more common in male sex which correlates with study done by Aiyar et al,14 Pinhero et al.,15 Eapen et al.5

In our study most common clinical presentation was hemiplegia which was followed by speech involvement. This observation closely correlates with the study done by P. Chitrambalam et al.,13 in which most common was hemiplegia (in $<45$ years $93.3 \%$, in $>45$ years $89.2 \%$ ) followed by speech involvement (in $<45$ years $43.3 \%$, in $>45$ years $30.8 \%$ ).

In our study most common risk factor was hypertension was the commonest risk factor which correlates with the study done by Eapen et al.,5 (40\%), Abdu-AlrhamanSallam et al.16 (67\%). In our study percentage of smoking \& alcohol were more as compared to other studies. The likely explanation is this being a 
retrospective study in few case histories those data was not filled properly by emergency duty doctors attending those pts.

In our study dyslipidemia was $42 \%$ which was more compared with study done by Eapen et al. (17\%),5 Abdu-AlrhamanSallam et al. (13.9\%).16 In our study diabetes pts were $45.5 \%$ which is drastically more compared with study done by Maskey et al. (9.3\%)9, Gauri et al. (9\%)12 and Eapen et al. (8\%).5 In our study pts with previous $\mathrm{H} / \mathrm{o}$ coronary artery disease were $26.5 \%$ which is also more when compared with study done by Kaur et al. (6\%)17 and Eapen et al. (9\%).5

In our study most common type of stroke was ischemic that is cerebral infarction (77\%) which correlated with studies done by Aiyaret al.14 in which infarction was in 70\%, in Eapenet al.5 $68 \%$ and in Devichand et al. $(75 \%) .18$

Second most common type of stroke was hemorrhagic (23\%) which correlated with study done by Eapenet al.5 (32\%), Aiyar et al.14 (26\%), Devichand et al. (25\%).18In our study most common site of hemorrhage was capsuloganglionic (21.7\%) followed by parietal (17.4\%). This findings correlates with study done by Eapenet al.5 and Aiyeret al.14 where it has been concluded that in multiple hematoma sites most common was thalamic ganglionic region.In our study most common site of infarct was capsuloganglionic (37\%), followed by parietal (18.2\%) followed by external capsule (10.4\%). These findings were favoring middle cerebral artery territory; this was also confirmed in study done by Devichand et al. and Caroliet al.18

\section{Conclusion}

To conclude stroke in our county is on rise. The occurrence rises with age with peak between 51 to 60 years. Young pts (age $\leq 40$ years) were $11 \%$ of pts which is more dangerous in view of productive year lost. This study showed male predominance in stroke cases. Cerebral infarction was more than hemorrhage. Males were more affected than females in ischemic stroke but for hemorrhage, incidence was equal. Hypertension was amongst leading risk factors for both types. Most common clinical presentation was hemiplegia followed by speech involvement. We need holistic approach \& more research to combat this deadly \& disabling disease.

\section{References}

[1]. S. Hartona. Experiences from a multicenter stroke register: a preliminary report. Bull WHO. 1976;54(5):541-53.

[2]. P. Bath. Acute stroke. In: D. Machin, S. Day S. Green, eds. Textbook of Clinical Trials. 2nd ed. Hoboken: Wiley; 2006: 179-180.

[3]. S. K. Das, T. K. Banerjee, A. Biswas, D. K. Raut, C. S. Mukherjee, A. Chaudhari, et al. A prospective com-munity based study of stroke in Kolkata, India. Stroke. 2007;38(3):906-10.

[4]. D. Nagaraja, G. Gururaj, N. Girish, Samhita Panda, A.K. Roy, G.R.K. Sarma, et al. Feasibility study of stroke surveillance: data from Bangalore, India. Indian J Med Res. 2009 Oct;130:396-403.

[5]. R. P. Eapen, J. H. Parikh, N. T. Patel. A study of clinical profile and risk factors of cerebrovascular stroke.Guj Med J. 2009;64(2):47-54.

[6]. Prasad Kameshwar, Singhal Kapil K. Stroke in young: an Indian perspective. Neurol India. 2010;58(3):343-50.

[7]. Feigin V, Lawes C, Bennet D, Barker Cello S, Parag V. Worldwide stroke incidence and early case fatality in 56 population based studies: a systematic review. Lancet Neurol. 2009;8(4):355-69.

[8]. Shah B, Mathur P. Workshop report on stroke surveillance in India. In: Shah B, Mathur P, eds. WHO Report. New Delhi: Division of Non Communicable Diseases, Indian Council of Medical Research; 2006: 1-33.

[9]. Maskey A, Parajuli M, Kohli SC. A study of risk factors of stroke in patients admitted in manipal teaching hospital, Pokhara. Kathmandu Univ Med J (KUMJ). 2011 Oct-Dec;9(36):244-7.

[10]. Awad SM, Al-Jumaily HF, Al-Dulaimi KM, Abdulghafoor RH. Assessment of major risk factors among stroke patients. Saudi Med J. 2010 Sep;31(9):1028-31.

[11]. Ukoha OB, Ajaegbu O, Eke CO. A review of stroke cases in a military hospital in Nigeria. AFRIMEDIC J. 2012 July-Dec;3(2):303.

[12]. Gauri LA, Kochar DK, Joshi A, Jain R, Gupta S, Saini G, et al. A study of risk factors \& clinical profile of stroke at Bikaner.J API. 2000 Jan;48(1).

[13]. P. Chitrambalam, DiptiBaskar, S. Revathy. A study on stroke in young and elderly in Rajiv Gandhi government general hospital, Chennai.Int J Clin Med. 2012;3:184-9.

[14]. Aiyar et al. A study of clinic-radiological correlation in cerebrovascular stroke (A study of 50 cases).Guj Med J. 1999 Mar;52:5863.

[15]. Pinhero L, Damodar S, Roy AK. Risk factors in stroke: a prospective study. J Assoc Physician India. 2000 Jan;48:72-6.

[16]. Abdul-Rahman Sallam, Khalid Al-Aghbari. The clinical profile of stroke: a Yemeni experience. J Med J. 2009;43(2):115-21.

[17]. Kaur IR, Agarwal MP, Singh NR. Study of clinical profile \& CT correlation in CV stroke.JAssoc Physician India. 2001;51:112-7.

[18]. Devichand, Karoli RK. A study of cerebrovascular strokes. J Indian Med Assoc. 1991 Jan;36(12):62-5. 